\title{
Dilemas e desafios da Proteção Internacional dos Direitos Humanos no limiar do século XXI
}

ANTÔNIO AUGUSTO CANÇADOTRINDADE*

No próximo ano estará a Declaração Universal de Direitos Humanos completando seu cinqüentenário, no limiar do novo século. Ao longo das cinco últimas décadas testemunhamos o processo histórico de gradual formação, consolidação, expansão e aperfeiçoamento da proteção internacional dos direitos humanos, conformando um direito de proteção dotado de especificidade própria. Este processo partiu das premissas de que os direitos humanos são inerentes ao ser humano, e como tais antecedendo a todas as formas de organização política, e de que sua proteção não se esgota na ação do Estado. Ao longo deste meio século, como respostas às necessidades de proteção, têm-se multiplicado os tratados einstrumentos de direitos humanos, a partir da Declaração Universal de 1948, tida como ponto de partida do processo de generalização da proteção internacional dos direitos humanos. O presente trabalho pretende proceder a um balanço, baseado na experiência acumulada nesta área, dos dilemas e desafios da proteção internacional dos direitos humanos no limiar do novo século.

A primeira Conferência Mundial de Direitos Humanos (Teerã, 1968) representou, de certo modo, a gradual passagem da fase legislativa, de elaboração dos primeiros instrumentos internacionais de direitos humanos (a exemplo dos dois Pactos das Nações Unidas de 1966), à fase de implementação de tais instrumentos. A segunda Conferência Mundial de Direitos Humanos (Viena, 1993) procedeu a uma reavaliação global da aplicação de tais instrumentos e das

Rev. Bras. Polít. Int. 40 (1): 167-177 [1997].

* Ph.D. (Cambridge); Juiz da Corte Interamericana de Direitos Humanos; Professor Titular da Universidade de Brasília e do Instituto Rio-Branco; Membro dos Conselhos Diretores do Instituto Interamericano de Direitos Humanos (Costa Rica) e do Instituto Internacional de Direitos Humanos (Estrasburgo). 
perspectivas para o novo século, abrindo campo ao exame do processo de consolidação e aperfeiçoamento dos mecanismos de proteção internacional dos direitos humanos. Decorridos quatro anos desta última Conferência, encontramse os órgãos internacionais de proteção dos direitos humanos diante de dilemas e desafios, próprios de nossos dias, que relacionaremos a seguir.

Cabe, de início, ter sempre presente que, nas últimas décadas, graças à atuação daqueles órgãos, inúmeras vítimas têm sido socorridas. Até o início dos anos noventa, no plano global (Nações Unidas), por exemplo, mais de 350 mil denúncias revelando um "quadro persistente de violações" de direitos humanos foram enviadas às Nações Unidas (sob o chamado sistema extraconvencional da resolução 1503 do ECOSOC). Sob o Pacto de Direitos Civis e Políticos e seu [primeiro] Protocolo Facultativo, o Comitê de Direitos Humanos tinha recebido, até abril de 1995, mais de 630 comunicações, e em $73 \%$ dos casos examinados concluiu que haviam ocorrido violações de direitos humanos. O Comitê para a Eliminação de Todas as Formas de Discriminação Racial tinha examinado (sob a Convenção do mesmo nome), a seu turno, em suas duas primeiras décadas de operação, 810 relatórios (periódicos e complementares) dos Estados Partes. E o Alto Comissariado das Nações Unidas para os Refugiados (ACNUR), decorridas quatro décadas de operação do sistema, cuida hoje de mais de 17 milhões de refugiados em todo o mundo ${ }^{1}$, sem falar no total ainda maior de deslocados internos.

No plano regional, por exemplo, até o início desta década, no continente europeu, a Comissão Européia de Direitos Humanos tinha decidido cerca de 15 mil reclamações individuais sob a Convenção Européia de Direitos Humanos, ao passo que a Corte Européia de Direitos Humanos totalizava 191 casos submetidos a seu exame, com 91 casos pendentes. No continente americano, a Comissão Interamericana de Direitos Humanos ultrapassava o total de 10 mil comunicações examinadas, enquanto a Corte Interamericana de Direitos Humanos, hoje com 14 pareceres emitidos, passava a exercer regularmente sua competência contenciosa, contando hoje com onze casos contenciosos pendentes. E, no continente africano, a Comissão Africana de Direitos Humanos e dos Povos examinava quase 40 reclamações ou comunicações sob a Carta Africana de Direitos Humanos e dos Povos ${ }^{2}$, algumas das quais já decididas.

Graças aos esforços dos órgãos internacionais de supervisão nos planos global e regional, logrou-se salvar muitas vidas, reparar muitos dos danos denunciados e comprovados, pôr fim a práticas administrativas violatórias dos direitos garantidos, alterar medidas legislativas impugnadas, adotar programas educativos e outras medidas positivas por parte dos governos. Não obstante 
todos estes resultados, estes órgãos de supervisão internacionais defrontam-se hoje com grandes problemas, gerados em parte pelas modificações do cenário internacional, pela própria expansão e sofisticação de seu âmbito de atuação, pelos continuados atentados aos direitos humanos em numerosos países, pelas novas e múltiplas formas de violação dos direitos humanos que deles requerem capacidade de readaptação e maior agilidade, e pela manifesta falta de recursos humanos e materiais para desempenhar com eficácia seu labor.

Os tratados de direitos humanos das Nações Unidas têm, com efeito, constituído a espinha dorsal do sistema universal de proteção dos direitos humanos, devendo ser abordados não de forma isolada ou compartimentalizada, mas relacionados uns aos outros. Decorridos quatro anos desde a realização da II Conferência Mundial de Direitos Humanos, estamos longe de lograr a chamada "ratificação universal" das seis "Convenções centrais" (core Conventions) das Nações Unidas (os dois Pactos de Direitos Humanos, as Convenções sobre a Eliminação de Todas as Formas de Discriminação-Racial e contra a Mulher, - a Convenção contra a Tortura, e a Convenção sobre os Direitos da Criança), - “ratificação universal” esta propugnada pela Conferência de Viena para o final de século que já vivemos. Ademais, encontram-se estas Convenções crivadas de reservas, muitas das quais, em nosso entender, manifestamente incompatíveis com seu objeto e propósito. Urge, com efeito, proceder a uma ampla revisão do atual sistema de reservas a tratados multilaterais consagrado nas duas Convenções de Viena sobre Direito dos Tratados (de 1969 e 1986), - sistema este, a nosso modo de ver, inteiramente inadequado aos tratados de direitos humanos.

A despeito da aceitação virtualmente universal da tese da indivisibilidade dos direitos humanos, persiste a disparidade entre os métodos de implementação internacional dos direitos civis e políticos, e dos direitos econômicos, sociais e culturais. Apesar da conclamação da Conferência de Viena, o Pacto de Direitos Econômicos, Sociais e Culturais, e a Convenção sobre a Eliminação de Todas as Formas de Discriminação contra a Mulher, continuam até o presente desprovidos de um sistema de petições ou denúncias internacionais. Os respectivos Projetos de Protocolo nesse sentido se encontram virtualmente concluídos, mas ainda aguardam aprovação. Muitos dos direitos consagrados nestes dois tratados de direitos humanos são perfeitamente justiciáveis por meio do sistema de petições individuais, e urge que se ponha um fim à referida disparidade de procedimentos.

É inadmissível que continuem a ser negligenciados em nossa parte do mundo, como o têm sido nas últimas décadas, os direitos econômicos, sociais e culturais. O descaso com estes últimos é triste reflexo de sociedades marcadas 
por gritantes injustiças e disparidades sociais. Não pode haver Estado de Direito em meio a políticas públicas que geram a humilhação do desemprego e o empobrecimento de segmentos cada vez mais vastos da população, acarretando a denegação da totalidade dos direitos humanos em tantos países. Não faz sentido levar às últimas conseqüências o princípio da não-discriminação em relação aos direitos civis e políticos, e tolerar ao mesmo tempo a discriminação como “inevitável” em relação aos direitos econômicos e sociais. Apobreza crônica não é uma fatalidade, mas materialização atroz da crueldade humana. Os Estados são responsáveis pela observância da totalidade dos direitos humanos, inclusive os econômicos e sociais. Não há como dissociar o econômico do social e do político e do cultural.

Urge despojar este tema de toda retórica, e passar a tratar os direitos econômicos, sociais e culturais como verdadeiros direitos que são. Só se pode conceber a promoção e proteção dos direitos humanos a partir de uma concepção integral dos mesmos, abrangendo todos em conjunto (os direitos civis, políticos, econômicos, sociais e culturais). A visão atomizada ou fragmentada dos direitos humanos leva inevitavelmente a distorções, tentando postergar a realização dos direitos econômicos e sociais a um amanhã indefinido. A prevalecer o atual quadro de deterioração das condições de vida da população, a afligir hoje tantos países, poderão ver-se ameaçadas inclusive as conquistas dos últimos anos no campo dos direitos civis e políticos. Impõe-se, pois, uma concepção necessariamente integral de todos os direitos humanos.

Uma das grandes conquistas da proteção internacional dos direitos humanos, em perspectiva histórica, é sem dúvida o acesso dos indivíduos às instâncias internacionais de proteção e o reconhecimento de sua capacidade processual internacional em casos de violações dos direitos humanos. Urge que se reconheça o acesso direto dos indivíduos àquelas instâncias (sobretudo as judiciais), a exemplo do estipulado no Protocolo ${ }^{\circ} 9$ à Convenção Européia de Direitos Humanos (1990). Concede este último um determinado tipo de locus standi aos indivíduos ante a Corte Européia de Direitos Humanos (em casos admissíveis que já foram objeto da elaboração de um relatório por parte da Comissão Européia de Direitos Humanos).

O passo seguinte, a ser dado no século XXI, consistiria na garantia da igualdade processual (equality of arms/égalité des armes) entre os indivíduos demandantes e os Estados demandados, na vindicação dos direitos humanos protegidos $^{3}$. Ao insistirmos não só na personalidade jurídica, mas igualmente na plena capacidade jurídica dos seres humanos no plano internacional, estamos sendo fiéis às origens históricas de nossa disciplina, o direito internacional (droit 
des gens), o que não raro passa despercebido dos adeptos de um positivismo jurídico cego e degenerado.

Dada a multiplicidade dos mecanismos internacionais contemporâneos de proteção dos direitos humanos, a necessidade de uma coordenação mais adequada entre os mesmos tem-se erigido como uma das prioridades dos órgãos de proteção internacional neste final de século. O termo “coordenação” parece vir sendo normalmente empregado de modo um tanto indiferenciado, sem uma definição clara do que precisamente significa; não obstante, pode assumir um sentido diferente em relação a cada um dos métodos de proteção dos direitos humanos em particular. Assim, em relação ao sistema de petições, a “coordenação” pode significar as providências para evitar o conflito de jurisdição, a duplicação de procedimentos e a interpretação conflitiva de dispositivos correspondentes de instrumentos internacionais coexistentes pelos órgãos de supervisão. No tocante ao sistema de relatórios, a “coordenação” pode significar a consolidação de diretrizes uniformes (concernentes à forma e ao conteúdo) e a racionalização e padronização dos relatórios dos Estados Partes sob os tratados de direitos humanos. E com respeito ao sistema de investigações (determinação dos fatos), pode ela significar o intercâmbio regular de informações e as consultas recíprocas entre os órgãos internacionais em questão ${ }^{4}$. A multiplicidade de instrumentos internacionais no presente domínio faz-se acompanhar de sua unidade básica e determinante de propósito, - a proteção do ser humano.

É inegável que, no presente domínio de proteção, muito se tem avançado nos últimos anos, sobretudo na “jurisdicionalização” dos direitos humanos, para a qual têm contribuído de modo especial os sistemas regionais europeu e interamericano de proteção, dotados que são de tribunais permanentes de direitos humanos, - as Cortes Européia e Interamericana de Direitos Humanos, respectivamente. No entanto, ainda resta um longo caminho a percorrer. Há que promover a chamada "ratificação universal” dos tratados de direitos humanos propugnada pelas duas Conferências Mundiais de Direitos Humanos(Teerã, 1968, e Viena, 1993), - contribuindo assim a que se assegure que a universalidade dos direitos humanos venha a prevalecer nos planos não só conceitual mas também operacional (a não-seletividade).

Para isto, é necessário que tal ratificação universal seja também integral, ou seja, sem reservas e com a aceitação das cláusulas facultativas, tais como, nos tratados que as contêm, as que consagram o direito de petição individual, e as que dispõem sobre a jurisdição obrigatória dos órgãos de supervisão internacional. Atualmente, todos os 40 Estados Partes na Convenção Européia de Direitos 
Humanos, além de aceitarem o direito de petição individual, reconhecem a jurisdição obrigatória da Corte Européia de Direitos Humanos, o que é alentador. Em contrapartida, no tocante à Convenção Americana sobre Direitos Humanos (em que o direito de petição individual é de aceitação automática pelos Estados Partes), lamentavelmente não mais que dezessete dos vinte e cinco Estados Partes reconhecem hoje a jurisdição obrigatória da Corte Interamericana de Direitos Humanos em matéria contenciosa.

O século $\mathrm{XX}$, que marcha célere para seu ocaso, deixará uma trágica marca: nunca, como neste século, se verificou tanto progresso na ciência e tecnologia, acompanhado paradoxalmente de tanta destruição e crueldade. Apesar de todos os avanços registrados nas últimas décadas na proteção internacional dos direitos humanos, têm persistido violações graves e maciças destes últimos. Às violações “tradicionais”, em particular de alguns direitos civis e políticos (como as liberdades de pensamento, expressão e informação, e o devido processolegal), que continuam a ocorrer, infelizmente têm se somado graves discriminações (contra membros de minorias e outros grupos vulneráveis, de base étnica, nacional, religiosa e lingüística), além de violações de direitos fundamentais e do direito internacionalhumanitário.

As próprias formas de violações dos direitos humanos têm sediversificado. Oque não dizer, por exemplo, das violações perpetradas por organismos financeiros e detentores do poder econômico, que, mediante decisões tomadas na frieza dos escritórios, condenam milhares de seres humanos ao empobrecimento, se não à pobreza extrema e à fome? O que não dizer das violações perpetradas por grupos clandestinos de extermínio, sem indícios aparentes da presença do Estado? O que não dizer das violações perpetradas pelos detentores do poder das comunicações? O que não dizer das violações ocasionadas pelo próprio progresso científicotecnológico? O que não dizer das violações perpetradas pelo recrudescimento dos fundamentalismos eideologias religiosas? O quenão dizer das violações decorrentes da corrupção e impunidade?

Cumpre conceber novas formas de proteção do ser humano ante a atual diversificação das fontes de violações de seus direitos. $\mathrm{O}$ atual paradigma de proteção (do indivíduo vis-à-vis o poder público) corre o risco de tornar-se insuficiente e anacrônico, por não se mostrar equipado para fazer frente a tais violações, - entendendo-se que, mesmo nestes casos, permanece o Estado responsável por omissão, por não tomar medidas positivas de proteção. Tem, assim, sua razão de ser, a preocupação corrente dos órgãos internacionais de proteção, no tocante às violações continuadas de direitos humanos, em desenvolver medidas tanto de prevenção como de seguimento, tendentes a cristalizar um 
sistema de monitoramento contínuo dos direitos humanos em todos os países, consoante os mesmos critérios.

A par da visão integral dos direitos humanos no plano conceitual, os esforços correntes em prol do estabelecimento e consolidação do monitoramento contínuo da situação dos direitos humanos em todo o mundo constituem, emúltima análise, a resposta, no plano processual, ao reconhecimento obtido na Conferência Mundial de Direitos Humanos de Viena em 1993 da legitimidade da preocupação de toda a comunidade internacional com as violações de direitos humanos em toda parte e a qualquer momento, - sendo este um grande desafio a defrontar o movimento internacional dos direitos humanos no limiar do século $\mathrm{XXI}^{5}$. Para enfrentá-lo, os órgãos internacionais de proteção necessitarão contar com consideráveis recursos - humanos e materiais - adicionais: os atuais recursos no plano global, menos de $1 \%$ do orçamento regular das Nações Unidas, -refletem um quase descaso em relação ao trabalho no campo da proteção internacional dos direitos humanos.

Os órgãos internacionais de proteção devem buscar bases e métodos adicionais de ação para fazer frente às novas formas de violações dos direitos humanos. A impunidade, por exemplo, verdadeira chaga que corrói a crença nas instituições públicas, é um obstáculo que ainda não conseguiram transpor. É certo que as Comissões da Verdade, instituídas nos últimos anos em diversos países, com mandatos e resultados de investigações os mais variáveis, constituem uma iniciativa positiva no combate a este mal, - mas ainda persiste uma falta de compreensão do alcance das obrigações internacionais de proteção. Estas últimas vinculam não só os governos (como equivocada e comumente se supõe), mas os Estados (todos os seus poderes, órgãos e agentes); é chegado o tempo de precisar o alcance das obrigações legislativas e judiciais dos Estados Partes em tratados de direitos humanos, de modo a combater com mais eficácia a impunidade.

Há, ademais, que impulsionar os atuais esforços, no seio das Nações Unidas, tendentes ao estabelecimento de uma jurisdição penal internacional de caráter permanente. Da mesma forma, há que desenvolver a jurisprudência internacional - ainda em seus primórdios - sobre as reparações devidas às vítimas de violações comprovadas de direitos humanos. O termo "reparações” não é juridicamente sinônimo de “indenizações”: o primeiro é o gênero, o segundo a espécie. No presente domínio de proteção, as reparações abarcam, a par das indenizações devidas às vítimas - à luz do princípio geral do neminem laedere, - a restitutio in integrum (restabelecimento da situação anterior da vítima, sempre que possível), a reabilitação, a satisfação e, significativamente, 
a garantia da não-repetição dos atos ou omissões violatórios (o dever de prevenção).

Para contribuir a assegurar a proteção do ser humano em todas $e$ quaisquer circunstâncias, muito se vem impulsionando, em nossos dias, as convergências entre o direito internacional dos direitos humanos, o direito internacional humanitário e o direito internacional dos refugiados. Tais convergências, motivadas em grande parte pelas próprias necessidades de proteção, têm se manifestado nos planos normativo, hermenêutico e operacional, tendendo a fortalecer o grau da proteção devida à pessoa humana. Face à proliferação dos atuais e violentos conflitos internos em tantas partes do mundo, já não se pode invocar a vacatio legis levando à total falta de proteção de tantas vítimas inocentes. A visão compartimentalizada das três grandes vertentes da proteção internacional da pessoa humana encontra-se hoje definitivamente superada; a doutrina e a prática contemporâneas admitem a aplicação simultânea ou concomitante das normas de proteção das referidas três vertentes, em benefício do ser humano, destinatário das mesmas. Passamos da compartimentalização às convergências. Cabe seguir avançando decididamente nesta direção ${ }^{6}$.

Os órgãos de supervisão internacional têm, ao longo dos anos, aprendido a atuar também em distúrbios internos, estados de sítio e situações de emergência em geral. Graças à evolução da melhor doutrina contemporânea, hoje se reconhece que as derrogações e limitações permissíveis ao exercício dos direitos protegidos, isto é, as previstas nos próprios tratados de direitos humanos, devem cumprir certos requisitos básicos. Podem estes resumir-se nos seguintes: tais derrogações e limitações devem ser previstas em lei (aprovada por um congresso democraticamente eleito), ser restritivamente interpretadas, limitarse a situações em que sejam absolutamente necessárias (princípio da proporcionalidade às exigências das situações), ser aplicadas no interesse geral da coletividade (ordre public, fim legítimo), ser compatíveis com o objeto e propósito dos tratados de direitos humanos, ser notificadas aos demais Estados Partes nestes tratados, ser consistentes com outras obrigações internacionais do Estado em questão, ser aplicadas de modo não-discriminatório e não-arbitrário, ser limitadas no tempo.

Em qualquer hipótese, ficam excetuados os direitos inderrogáveis (como o direito à vida, o direito a não ser submetido a tortura ou escravidão, o direito a não ser incriminado mediante aplicação retroativa das penas), que não admitem qualquer restrição. Do mesmo modo, impõe-se a intangibilidade das garantias judiciais em matéria de direitos humanos (exercitadas consoante os 
princípios do devido processo legal), mesmo em estados de emergência. O ônus da prova do cumprimento de todos estes requisitos recai naturalmente no Estado que invoca a situação de emergência pública em questão. Em casos não previstos ou regulamentados pelos tratados de direitos humanos e de direito humanitário, impõem-se os princípios do direito internacional humanitário, os princípios de humanidade e os imperativos da consciência pública. Aos órgãos de supervisão internacional está reservada a tarefa de verificar e assegurar o fiel cumprimento desses requisitos pelos Estados que invocam estados de sítio ou emergência, mediante, e.g., a obtenção de informações mais detalhadas a respeito e sua mais ampla divulgação (inclusive das providências tomadas), e a designação de relatores especiais ou órgãos subsidiários de investigação dos estados ou medidas de emergência pública prolongados ${ }^{7}$.

As iniciativas no plano internacional não podem se dissociar da adoção e do aperfeiçoamento das medidas nacionais de implementação, porquanto destas últimas - estamos convencidos - depende em grande parte a evolução da própria proteção internacional dos direitos humanos. A responsabilidade primária pela observância dos direitos humanos recai nos Estados, e os próprios tratados de direitos humanos atribuem importantes funções de proteção aos órgãos dos Estados. Ao ratificarem tais tratados, os Estados Partes contraem a obrigação geral de adequar seu ordenamento jurídico interno à normativa internacional de proteção ${ }^{8}$, a par das obrigações específicas relativas a cada um dos direitos protegidos.

No presentedomínio de proteção, o direito internacional e o direito interno se mostram, assim, em constante interação. É a própria proteção internacional que requer medidas nacionais de implementação dos tratados de direitos humanos, assim como o fortalecimento das instituições nacionais vinculadas à vigência plena dos direitos humanos e do Estado de Direito. De tudo isto se pode depreender a premência da consolidação de obrigações erga omnes de proteção, consoante uma concepção necessariamente integral dos direitos humanos.

Enfim, ao voltar os olhos tanto para trás como para frente, apercebemonos de que efetivamente houve, nestas cinco décadas de experiência acumulada nesta área, um claro progresso, sobretudo na jurisdicionalização da proteção internacional dos direitos humanos, - mas, ainda assim, também nos damos conta de que este progresso não tem sido linear. Tem havido momentos históricos de avanços, mas lamentavelmente também de retrocessos, quando não deveria haver aqui espaço para retrocessos.

Neste final de século, resta, certamente, um longo caminho a percorrer, tarefa para toda a vida. Uma fiel ilustração dos obstáculos que enfrenta a luta 
em prol da proteção internacional dos direitos humanos reside, a nosso ver, no mito do Sísifo, nas imorredouras reflexões de um dos maiores escritores deste século, Albert Camus. É um trabalho que simplesmente não tem fim. Trata-se, em última análise, de perseverar no ideal da construção de uma cultura universal de observância dos direitos humanos, do qual esperamos nos aproximar ainda mais, no decorrer do século XXI, graças ao labor das gerações vindouras que não hesitarão em abraçar a nossa causa.

Maio de 1997

\section{Notas}

1 Para um exame destes e outros dados, cf. A.A. Cançado Trindade, Tratado de Direito Internacional dos Direitos Humanos, volume I, Porto Alegre, S.A. Fabris Ed., 1997, capítulo II, p. 61 e seguintes.

2 Cf. ibid., pp. 62-63.

3 A.A. Cançado Trindade, Tratado de Direito Internacional..., op. cit., supra n. (3), pp. 84-85.

4 Para um amplo estudo, cf. A.A. Cançado Trindade, “Co-existence and Co-ordination of Mechanisms of International Protection of Human Rights (At Global and Regional Levels)", 202 Recueil des Cours de l'Académie de Droit International -Haia (1987) pp. 13-435.

5 A.A. Cançado Trindade, “A Proteção Internacional dos Direitos Humanos ao Final do Século XX”, in A Proteção Nacional e Internacional dos Direitos Humanos (Seminário de Brasília de 1994, orgs. Benedito Domingos Mariano e Fermino Fechio Filho), São Paulo, FIDEH/Centro Santos Dias de Direitos Humanos, 1995, pp.112-115.

6 A.A. Cançado Trindade, Gérard Peytrignet e Jaime Ruiz de Santiago, As Três Vertentes da Proteção Internacional dos Direitos da Pessoa Humana, San José/ Brasília, IIDH/CICV/ACNUR, 1996, pp. 117-121.

7 A.A. Cançado Trindade, A Proteção Internacional dos Direitos Humanos Fundamentos Jurídicos e Instrumentos Básicos, São Paulo, Ed. Saraiva, 1991, pp. 16-17.

8 No tocante ao direito brasileiro, cf. A.A. Cançado Trindade (Editor), AIncorporação das Normas Internacionais de Proteção dos Direitos Humanos no Direito Brasileiro (Seminários de Brasília e Fortaleza de 1993), 2ª . edição, Brasília/San José, IIDH/CICV/ACNUR/CUE/ASDI, 1996, pp. 7-845; A.A. Cançado Trindade (Editor), A Proteção dos Direitos Humanos nos Planos Nacional e Internacional: Perspectivas Brasileiras, San José/Brasília, IIDH/Fund. F. Naumann, 1991, 
pp. 1-357; Flávia Piovesan, Direitos Humanos e o Direito Constitucional Internacional, São Paulo, Max Limonad, 1996, pp. 11-332; Celso D. deAlbuquerque Mello, Direito Constitucional Internacional, Rio de Janeiro, Ed. Renovar, 1994, pp. 165-191.

Resumo

Balanço dos avanços conceituais e práticos e das limitações ainda existentes, de ordem legal ou política, à proteção universal dos direitos humanos, ressaltando a construção progressiva dos instrumentos disponíveis - as convenções centrais - e o papel das conferências e das cortes regionais de defesa dos direitos humanos.

\section{Abstract}

Review of the conceptual and practical progresses and the restrictions that still exists, of legal or political order, to the universal protection of human rights, emphasizing the progressive building of the available instruments - the central conventions and the role of the conferences and regional courts of human rights defense.

Palavras-chave: Direitos humanos. Proteção legal. Cortes regionais. Key-words: Human rights. Legal protection. Regional courts. 